\title{
Assessing the Efficiency of an Insurance Provider-A Measurement Error Approach
}

\author{
MARIO JAMETTI \\ jametti@mcmaster.ca \\ McMaster University, 1280 Main Street West, Hamilton, Ontario, L8S 4M4, Canada \\ THOMAS VON UNGERN-STERNBERG \\ Thomas.vonUngern-Sternberg@unil.ch \\ HEC-Université de Lausanne and CESifo, BFSH1, 1015 Lausanne, Switzerland
}

Received January 3, 2003; Revised January 7, 2004

\begin{abstract}
The purpose of this paper is to compare the cost efficiency of private and public property insurance providers in Switzerland. The most commonly used measure for this kind of exercise is the claims-premium ratio. We argue that this measure may give strongly biased results. We develop a simple model to test whether the elasticity of premiums with respect to claims is less than unity. We address the fact that premium income is relatively stable across time, while claims are not, using estimation techniques that correct for measurement error. We develop tools to cope with heteroskedasticity in such measurement errors and apply the model to a data set on 19 firms in housing insurance markets in Switzerland. We show that the public insurance providers are about $20 \%$ more cost efficient than their private counterparts.
\end{abstract}

Key words: insurance, public and private, cost efficiency, C/P ratio, measurement error, CALS

JEL Classification No.: C21, D21, L84

\section{Introduction}

The purpose of this paper is to compare the cost efficiency of private and public insurance providers on the Swiss property insurance market. The most commonly used indicator to perform this kind of comparison is the claims-premium ratio $(\mathrm{C} / \mathrm{P}$ ratio, see e.g. Association of British Insurers [1996]; Fédération Française des Sociétés d'Assurance [1998]; UNESPA [1994]), i.e. the percentage of premium revenue that the insurer spends on claims payments. The higher this percentage is, the lower the fraction the insurer needs for other purposes such as administrative costs, commissions, reserves or profits. The main advantage of this ratio is its simplicity. It does, however, have a number of drawbacks. First, insurance contracts of small value (e.g. travel luggage insurance) typically require much higher sales and administrative costs per unit insured than contracts where the sum insured is large (e.g. property insurance). ${ }^{1}$ This implies that, even for efficient firms, the $\mathrm{C} / \mathrm{P}$ ratio should vary across insurance products, and hence simple comparison across segments of the industry is not warranted. Second, even within a given type of insurance contract there is no a priori reason why the premium level should increase proportionately with claims. For the problem 
we wish to address in this paper, this is an empirically important issue. Indeed, on the Swiss property insurance market the private suppliers have average claims levels that are roughly $50 \%$ higher than those of the public insurance providers.

At a conceptual level, one can convincingly argue that the elasticity of premiums with respect to claims should be less than unity. To illustrate this we decompose the use made of the premium income of an insurance company into the following three components: (a) claims payments, (b) reserves and profits and (c) administrative costs and commissions. This last component is the most illustrative for our point. As regards the commissions paid to the insurance brokers, there is no good reason why these should increase with claims payments. Quite to the contrary, the effort of an insurance broker is, as a first approximation, independent of the level of claims. One might be tempted to go even further and argue that there should be a negative relationship, as the insurance provider has an incentive to attract "good risks". Similarly, the administrative costs of an insurance company can be decomposed into two parts: first the cost of acquiring customers, which should be independent of the claims level; and second the cost of settling claims, which should increase with the number of claims and presumably decrease with the average size of each claim. These considerations would seem to indicate that a simple linear regression of the level of premiums on the level of claims should have a positive intercept and hence the C/P ratio would vary with the level of claims.

A further issue is that, for many types of insurance, the level of claims can fluctuate substantially from one year to the next. However, it is quite intuitive that the insurance company's actions (e.g. the staff it employs for settling claims and its administrative infrastructure), are a function of the "normal" or "permanent" level of claims payments. Observed payments can be considered as a noisy signal of this "permanent" level. This raises a methodological problem. If we were to regress annual premium rates on annual claims rates, we would obtain a slope coefficient with a strong downward bias, because of measurement error problems. A number of authors [Kirchgässner, 1996; Schips, 1995; von Ungern-Sternberg, 1994] have therefore decided to work with ten-year averages rather than annual data. Actually Schips [1995] goes even further, stating that at least ten-year averages need to be taken into account. The use of ten-year averages should reduce the importance of the problems noted above, but not eliminate them. The ten-year average, while being a more precise signal of the underlying level of "permanent" claims, is still a noisy signal. One way to solve this problem would be to resort to Instrumental Variables (IV) techniques.

Note that working with IV does not make use of all the information contained in the data. Specifically, it could be the case that for some insurance companies the variability of claims payments is much greater than for others. It should be possible to use this information to obtain a more precise estimator of the relationship between administrative costs and "normal" claims payments. An alternative estimation technique, consistent adjusted least squares (CALS), allows to introduce such considerations.

We propose to empirically study these issues using data on 19 regionally separated housing insurance markets (cantons) in Switzerland. Each of these markets corresponds to a state owned monopoly (the Cantonal Property Insurance, CPI) with perfectly inelastic demand, since housing insurance is compulsory. We will develop unbiased estimators of the relationship between administrative costs and claims payments on one hand, and premium income 
and claims payments on the other. As regards premium income, a further distinction will be introduced: The Cantonal Property Insurances spend a large part of their premium income to finance prevention (firefighting). We will thus distinguish between gross premiums (including expenditures on prevention) and net premiums (net of expenditures on prevention).

We will use the estimates we obtain to compare the cost efficiency of the Cantonal Property Insurances with the private insurance providers active in the 7 Cantons that have no state monopoly provider. We come to the conclusion that the cantonal property insurance providers are approximately $20 \%$ less expensive than their private counter parts, even if we consider that the difference in claims rates is exogenous, i.e. independent of the expenditures on prevention. This fraction is considerably larger than the result from the simple comparison of the $\mathrm{C} / \mathrm{P}$ ratio.

From a methodological point of view, our paper can be seen as a contribution to the (large) literature on measurement error in economics, much of which has been developed around the topic of permanent income (e.g. Abul Naga [2000] on intergenerational mobility). The novelty of our work is the fact that we explicitly use the information we have on the degree of noisiness of the observed signal to obtain a more efficient estimator. This has, to our knowledge, not been done in the literature so far.

The issue of the cost efficiency of property insurance providers has been taken up by several authors. Regarding the Swiss market there has been an academic discussion in the middle of the 1990's by Schips [1995], von Ungern-Sternberg [1994, 1995] and Kirchgässner [1996]. Von Ungern-Sternberg took the stand for the public firms, arguing that they produced similar quality of service but at a significantly lower premium rate. Schips in turn took the stand of the private firms, claiming that relative to the observed damage payments the public monopolies had a higher mark-up. Finally, the third contributor to this academic discussion, Kirchgässner, rather favoured the arguments of von Ungern-Sternberg. It is interesting to note that all three authors were interested in the relationship between the level of claims payments and components of costs or premium levels, but reached contradictory results.

Further, it is useful to mention two other studies concerning the German housing insurance market, which experienced an opening of monopoly markets to competition. Felder [1996] compares the price-performance of public monopolies and private firms in Germany. He finds that on average the monopoly firms have significantly lower mark-ups than the firms in competitive regions. Epple and Schäfer [1996] look at the transition from public monopoly to competition in Germany after the implementation of the third EU damage guideline. They find that premium rates increased dramatically through this transition.

A more general treatment of issues arising in housing insurance throughout Europe can be found in von Ungern [2004].

The remainder of the paper is structured as follows: Section 2 presents the economic problem we are interested in. In Section 3 we present in more detail the data at hand from the housing insurance market in Switzerland. Section 4 introduces the model and its assumptions we will use in the empirical part of the paper. It also includes tests whether these assumptions are confirmed within the data set. Section 5 presents the estimation techniques used and the discussion of the results, while Section 6 presents the results on the comparison between the cost structure of public and private insurance providers. Section 7 concludes. 


\section{The economic problem}

We wish to compare the cost efficiency of public and private insurance providers on the Swiss property insurance market. ${ }^{2}$ The structure of the market is as follows: Housing insurance is compulsory for every building. In 19 of the 26 Swiss cantons there is a public state monopoly, the Cantonal Property Insurance (CPI). In the remaining 7 Cantons there is no public supplier, and the owners have to obtain cover from one of several private insurance companies. ${ }^{3}$ Most CPIs have existed for over 200 years. Similarly, the cantons which currently operate with private firms have never had a monopoly. The reason for these decisions vary across cantons, but are mainly historical.

A rough comparison of the cost structure of the different types of insurance can be found in Figure 1. Costs are expressed in cts per SFr. 1'000 housing stock insured (SI).

A first important point to note is that the private insurance companies spend substantially more on administrative costs and commissions than their public counterparts. (31 cts vs. $6 \mathrm{cts} / \mathrm{SFr}$. 1'000 SI). This difference is easy to explain. The state monopolies have a very stable customer base (the house owners of their canton) and they have no need to invest into customer acquisition and advertising. This gives them a substantial cost advantage.

Second, one notes that the Cantonal Property Insurances spend important amounts on damage prevention. They devote roughly one quarter of their premium income $(14 \mathrm{cts} / \mathrm{SFr}$. 1 '000 SI) on such activities. This seems to us an interesting application of the Coase theorem (Coase [1960]). The public insurance companies benefit directly from better prevention. They are thus more likely to devote the necessary resources to such activities. The private insurance companies spend only slightly more than the compulsory 5 cent tax ("Löschfünfer") on prevention. Finally one notes that the claims level of the private insurance companies is substantially higher than the one for the CPI. There is some debate in Switzerland, to what extent this difference in claims levels can be attributed to differences in preventive measure.

Given these large cost differences, it is not surprising, that the CPI can work with much lower premium rates. For the period 1984-1995 the premium difference was of the order

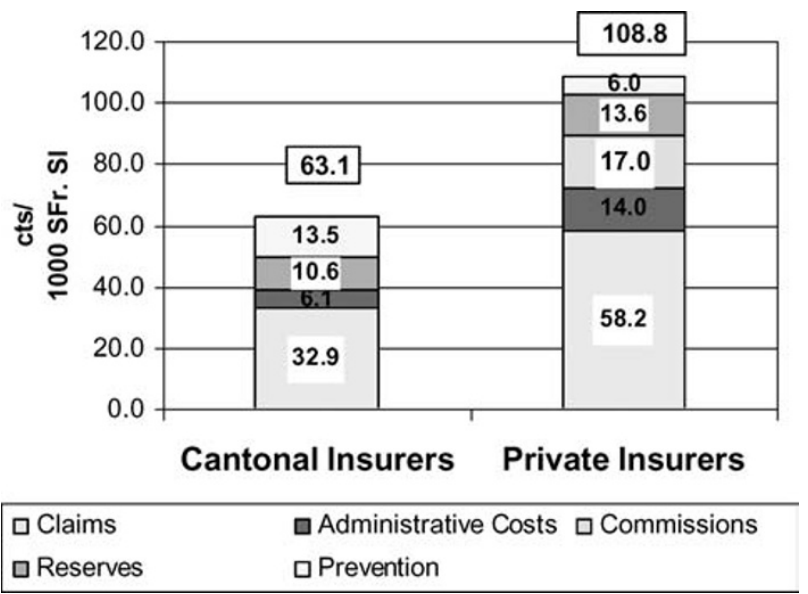

Figure 1. Comparison of premium rates. (Fire and natural disasters, 1984-1995). 
of $40 \%$. Further, the premiums for the CPI have fallen another $25 \%$ between 1995 and 1999. They are now at $46 \mathrm{cts} / \mathrm{SFr}$. 1'000 SI. For the private insurance companies we have no comparable figures, but there is circumstantial evidence that their premium rates have remained roughly constant. The premium differential is thus currently of the order of $55 \%$.

\section{The data}

In order to proceed with the comparison we dispose of a rather substantial data set for the CPIs, which is described below. This set allows us to perform the regression analysis to obtain a benchmark for comparison. Data for the private cantons are, unfortunately, not available in sufficient detail for a more elaborate comparison. However, we do have sufficient data to perform the essential comparisons which allow us to validate the main arguments of this paper (see Section 6).

The data set on the 19 CPIs in Switzerland covers the period 1981 to 1999. For each firm (canton) we have the annual values of: insured housing stock, claims paid (with a distinction between fire and elemental damage), premium income, prevention expenses and administrative costs. We express costs and damages as rates, i.e. per SFr.1'000 insured.

This gives us the following definitions of the variables used:

- $y 1_{i t}$ premiums per SFr. 1'000 SI for firm $i$ in year $t$.

- $y 2_{i t}$ net premiums per SFr. 1'000 SI for firm $i$ in year $t$, expressed as the difference between premiums and prevention expenses.

- $y 3_{i t}$ administrative costs per SFr. 1'000 SI for firm $i$ in year $t$.

- $x_{i t} \quad$ claims paid per SFr. 1'000 SI for firm $i$ in year $t$.

Data for premiums and claims correspond to current values, i.e. claims payments are accounted in the year of the corresponding damage. Some lag might exist between damage occurrence and corresponding administrative costs. We assume that this lag is negligible for all the years in the sample. An important exception to this was the storm Lothar in 1999, which passed Europe in the end of the year. It is very likely that an important part of administrative costs associated with this event were incurred in the following year, thus inducing biases in our model's result. We have excluded this year from the sample.

There are two reasons to express all the variables as rates. First, using total values could lead to biased results due to scale effects. Second, the data for the private firms were only available in this form.

Tables 1 and 2 present summary statistics of the variables. In Table 1 we present the disaggregated data, in Table 2 the same data for the 19 (unweighted) cantonal averages. The mean premium income is about $70 \mathrm{cts} / \mathrm{SFr}$. 1'000 SI. From the difference between premium income and net premium income we can infer that average spending on prevention is about 15.5 cts / SFr. 1'000 SI. Claims represent almost $50 \%$ of premium income, whereas administrative costs a little over $10 \%$.

From Table 2 we can see that claims payments are more volatile than premiums and administrative costs. Similarly, the coefficient of variation of claims is more than three times higher than the one for premium income. The coefficient of variation for claims is still more than double the ones for net premium income and administrative costs. 
Table 1. Summary statistics (cts per SFr. 1'000 SI).

\begin{tabular}{lrrrrr}
\hline Variable & Obs. & Mean & Std. dev. & Min & Max \\
\hline Prem. $\left(y 1_{i t}\right)$ & 342 & 70.29 & 17.12 & 27.66 & 109.88 \\
Net Prem. $\left(y 2_{i t}\right)$ & 342 & 54.59 & 18.63 & 6.56 & 95.25 \\
Adm. Costs $\left(y 3_{i t}\right)$ & 342 & 7.38 & 2.88 & 2.88 & 17.83 \\
Claims $\left(x_{i t}\right)$ & 342 & 34.64 & 19.90 & 5.99 & 126.09 \\
\hline
\end{tabular}

Table 2. Summary statistics—cantonal averages (cts per SFr. 1'000 SI).

\begin{tabular}{lcccrr}
\hline Variable & Obs. & Mean & Coeff. variation & Min & Max \\
\hline Prem. $\left(y 1_{i t}\right)$ & 19 & 70.29 & 0.12 & 39.29 & 95.61 \\
Net Prem. $\left(y 2_{i t}\right)$ & 19 & 54.59 & 0.20 & 29.70 & 84.30 \\
Adm. Costs $\left(y 3_{i t}\right)$ & 19 & 7.38 & 0.17 & 3.76 & 13.51 \\
Claims $\left(x_{i t}\right)$ & 19 & 34.64 & 0.44 & 18.39 & 60.04 \\
\hline
\end{tabular}

\section{The model}

The private insurance companies tend to interpret the numbers shown in Figure 1 (Section 2) somewhat differently. They argue that the claims-premium ratio ( $\mathrm{C} / \mathrm{P}$ ratio) of the private insurance companies is equal to 0.53 which is almost the same as that for the CPI (0.52). ${ }^{4}$

This comparison is probably biased, since it implicitly treats the considerable expenses for preventive measures financed by the CPI in the same way as expenditures on, say, advertising and commissions. It ignores the fact that the purpose of preventive measures is to reduce damages. If one were to subtract the expenses on prevention for both types of insurance, the claims ratios would be 0.66 for the CPI and 0.57 for the private insurers, a difference of only about $15 \%$. This raises the question, whether the C/P ratio is indeed an adequate method of comparison.

The underlying assumption of the $\mathrm{C} / \mathrm{P}$ ratio is that all the other cost components of an insurance provider (in our case administrative costs, commissions and reserves) vary proportionately with the level of claims. This need not necessarily be the case. We argued in the introduction, that there are good reasons to believe that the elasticity of both administrative costs and premiums with respect to claims should be less than one.

Whether this is in fact the case, is an empirical issue. We will analyze how administrative costs, gross premium and net premium (net of prevention costs) rates vary with claims rates. We will use the results obtained, to estimate administrative costs, gross premiums and net premiums for a hypothetical CPI, which would have to work with the claims rates incurred by the private insurance providers. We shall compare these results with the cost differential implied by the $\mathrm{C} / \mathrm{P}$ ratio. We show that the results obtained by the latter measure considerably underestimate the "true" differential obtained from our regression analysis.

The main econometric problem of this approach is the fact that the level of damages in the property insurance market varies considerably from year to year. There are good theoretical 
reasons why the insurance companies' administrative costs and premium levels are more stable than claims payments. Insurance companies will determine their administrative costs and premium not on the basis of annual claims levels but of permanent or expected long run claims levels. When regressing annual premiums or administrative costs on annual claims levels in each of the 19 cantons, the slope coefficients are not significantly different from zero in 35 out of 38 cases. $^{5}$

We will therefore work with a model where the annual administrative costs or (gross or net) premium income for a specific firm is a function, not of the annual claims level, but the "permanent" level of claims. In the simplest form of a linear relationship, this can be expressed by

$$
y j_{i t}=\alpha+\beta x_{i}^{*}+u_{i t},
$$

where $y j_{i t}$ is the observed value of firm $i$ in year $t$ for: $j=1$ administrative cost, $j=2$ gross premium income and $j=3$ net premium income, $x_{i}^{*}$ is its permanent level of claims and $u_{i t}$ is the usual error term. The $x_{i}^{*}$ 's are unobserved by the econometrician, but known by the firm when it determines the size of its administrative staff and related actions. The information available to the econometrician is in the form of annual observations on claims payments. The yearly payments can be decomposed into the permanent level of claims $\left(x_{i}^{*}\right)$ and a stochastic component $\left(v_{i t}\right)$, which can be thought of as a "measurement error"

$$
x_{i t}=x_{i}^{*}+v_{i t}
$$

We assume $v_{i t}$ to be independent of both $x_{i}^{*}$ and $u_{i t}$, and not serially correlated. However, we do not specify explicit assumptions on the variance of the measurement error, allowing for heteroskedasticity. ${ }^{6}$

If the true relationship between administrative costs or premium income and the level of claims is given by (1), then an OLS regression based on

$$
y_{i t}=\alpha+\beta x_{i t}+\varepsilon_{i t}
$$

will lead to a slope coefficient which is biased towards zero. ${ }^{7}$ This well known result comes from the fact that the combined error term $\left(\varepsilon_{i t}=u_{i t}-\beta v_{i t}\right)$ is correlated with the regressor $x_{i t}$. The (multiplicative) bias can be expressed as a function of the second moments ${ }^{8}$ of the variables, and is given by

$$
\text { bias } b_{O L S}=\frac{\sigma_{v}^{2}}{\sigma_{x^{*}}^{2}+\sigma_{v}^{2}},
$$

which can be described as the noise-to-total-variance ratio.

An alternative to the above model is the use of time averages for each firm, i.e. estimating the model

$$
y_{i}=\alpha+\beta x_{i}+\varepsilon_{i}
$$


Table 3. Summary statistics of claims payments-Specific CPIs (cts per SFr. 1'000 SI).

\begin{tabular}{lclccr}
\hline Canton & Obs. & Mean & Coeff. var. & Min & Max \\
\hline Lucerne & 18 & 60.04 & 0.43 & 27.95 & 126.09 \\
Glarus & 18 & 38.9 & 0.57 & 11.92 & 89.87 \\
Zurich & 18 & 18.39 & 0.20 & 10.48 & 24.16 \\
\hline
\end{tabular}

where the variables are now time averages for each firm $i$. Standard regression delivers a better result in this case, but we still do not obtain a consistent estimate. The bias in this case is given by

$$
\text { bias } b_{A V E}=\frac{\sigma_{v}^{2} / T}{\sigma_{x^{*}}^{2}+\sigma_{v}^{2} / T} \text {, }
$$

Note that the estimates of all other parameters in such a model are biased as well. We therefore need different estimation procedures in order to get consistent estimates.

As mentioned before, damage occurrences vary greatly across regions. It is not only that the average claims level varies across CPIs, but also the variance of claims among the different CPIs is not the same. Table 3 illustrates this fact. The average claims level for the rural canton Lucerne is more than three times the one for the urban canton Zurich. Similarly, the coefficient of variation of another rural canton, Glarus, is almost triple compared to an urban area (Zurich). Figure 2 shows the evolution of claims in the years 1981 to 1998 for the same areas.

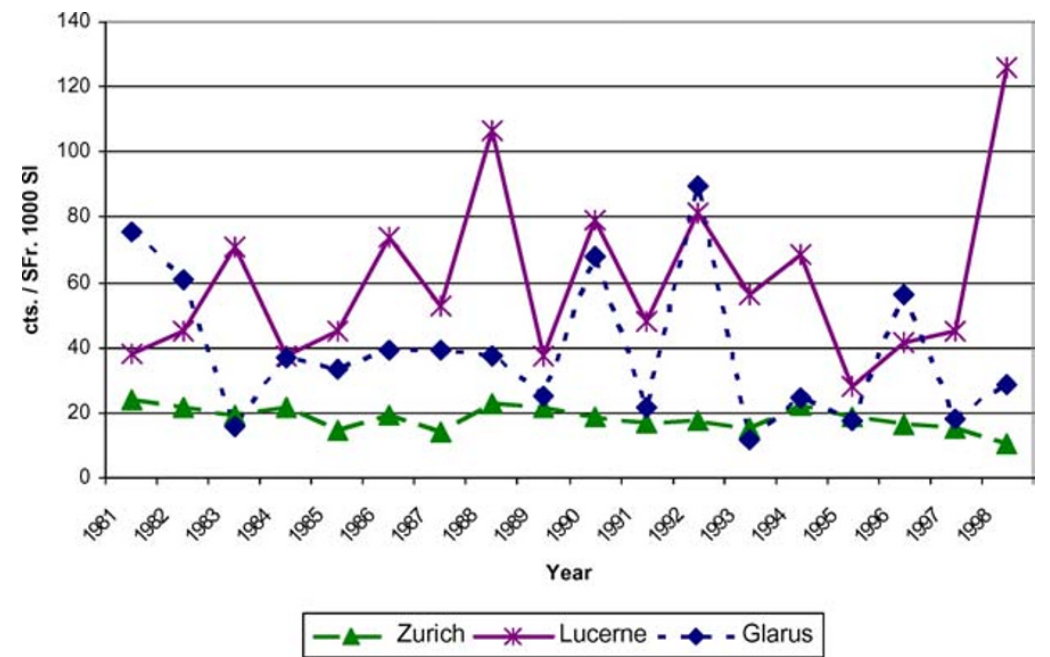

Figure 2. Evolution of claims payments-Specific CPIs 1981-1998. 
We thus wish to take into account the fact that the "measurement" error does not necessarily have the same variance across firms. We denote by $\sigma_{v i}^{2}$ the variance in the measurement error of firm $i$. Clearly, if we have information on $\sigma_{v i}^{2}$, this information should be used, if we wish to obtain an efficient estimator of the coefficients in the model.

\section{Estimation and results}

We apply two different estimation techniques to our model: the standard Instrumental Variables (IV) approach, and an alternative technique: Consistent Adjusted Least Squares (CALS). Both techniques yield consistent coefficient estimates and allow us to test to what extent the $\mathrm{C} / \mathrm{P}$ ratio can be used to assess efficiency of an insurance provider.

Both estimation procedures depart from OLS in that they use additional elements for estimation. In the case of IV it is the use of instruments, whereas in the case of CALS it is the variance of the measurement errors.

\section{Instrumental variables (IV)}

Instrumental Variables (IV) has become the most standard approach to measurement error problems. ${ }^{9}$ With suitable instruments it produces consistent estimates. The drawback of the technique is that "good" instruments are not always readily available, so the benefit of getting a consistent result is often obtained at the cost of an increased variance of the estimator.

As shown in Griliches and Hausman [1986], instruments are readily available in a panel data set. Given our assumptions, we can use, for every firm $i$, any observation at $\tau \neq t$ of the level of claims as an instrument for $x_{i t} .{ }^{10}$ This allows us to construct the following "valid" instrument ${ }^{11}$

$$
w_{i t}=\frac{1}{T-1} \sum_{\tau \neq t} x_{i \tau} .
$$

Further, to test for weak instruments, we performed a test as outlined in Staiger and Stock [1997]. This test indicated strongly that our instruments are not "weak". 12

Applying IV will produce a consistent estimator of the parameter values of our model. We further want to take into account heteroskedastic errors in the regression. We do this in a similar way as using robust standard errors with OLS. Following Wansbeek and Meijer [2000], an alternative IV-estimator, based on GMM can be applied in the case of heteroskedasticity of unspecified form. This estimator is based on IV and introduces the adjustment for heteroskedasticity in a two-step estimation procedure. The algebraic expression is

$$
b_{I V-G M M}=\left(X^{\prime} W\left(W^{\prime} \hat{\Psi}_{\varepsilon} W\right)^{-1} W^{\prime} X\right)^{-1} X^{\prime} W\left(W^{\prime} \hat{\Psi}_{\varepsilon} W\right)^{-1} W^{\prime} y,
$$

where $X$ and $W$ are the matrix of regressors and instruments, respectively, $\hat{\Psi}_{\varepsilon}=\operatorname{diag}\left[e^{2}\right]$, and $e^{2}=\left(y-b_{I V} x\right)^{2}$ is the squared error from the application of IV. However, since in our case the number of instruments is the same as the number of regressors, $W^{\prime} X$ is squared and 
the formula reduces to the standard IV-estimator. Nevertheless, the estimated covariance matrix of $b_{I V-G M M}$ is different and the estimator is asymptotically more efficient (see Wansbeek and Meijer [2000], p. 120).

\section{Consistent adjusted least squares (CALS)}

Consistent Adjusted Least Squares (CALS) is an alternative to IV estimation with some interesting features. It relies on the knowledge of the variance of the measurement error, and will allow us to take explicitly into account differences across firms in the accuracy of the observed signal on the permanent level of claims. This technique has been pioneered by Kapteyn and Wansbeek [1984].

The technique is intuitive and can best be illustrated on the slope coefficient $(\beta)$ of our model. OLS regression of (3) leads to biased results, as shown above. The probability limit of the OLS estimator is given by

$$
p l i m b_{O L S}=\beta \frac{\sigma_{x^{*}}^{2}}{\sigma_{x^{*}}^{2}+\sigma_{v}^{2}} .
$$

We can see that, with knowledge of the variance of the measurement error $\left(\sigma_{v}^{2}\right)$, one can obtain a consistent estimator based on OLS, which we denote by ${ }^{13}$

$$
b_{C A L S}=\left(1-\frac{\sigma_{v}^{2}}{s_{x}^{2}}\right)^{-1} b_{O L S}
$$

where $s_{x}^{2}=\frac{1}{N T} \sum_{i} \sum_{t} x_{i t}^{2}$ is the observed second moment of the level of claims. Note that similar adjustments can be applied to all the other coefficients of the model, in our case to $\alpha$.

As mentioned before, we can extend this framework to allow for heteroskedastic measurement error. If the variance of the measurement error $\left(\sigma_{v i}^{2}\right)$ is known, we can rewrite the true model in the following way

$$
\begin{aligned}
& \tilde{y}_{i}=\tilde{\alpha}+\beta \tilde{x}_{i}^{*}+\tilde{u}_{i} \\
& \tilde{x}_{i}=\tilde{x}_{i}^{*}+\tilde{v}_{i},
\end{aligned}
$$

where $\tilde{x}_{i}=\frac{\sqrt{T}}{\sigma_{v i}} \bar{x}_{i}$ and $\bar{x}_{i}$ is the sample average over firm $i$. The other variables are defined analogously. Note that with this transformation we have $E\left[\tilde{v}_{i t}^{2}\right]=1$, i.e. the measurement error variance is the same across firms and known. Joining (11) and (12) results in the equation to be estimated: ${ }^{14}$

$$
\tilde{y}_{i}=\tilde{\alpha}+\beta \tilde{x}_{i}+\tilde{\varepsilon}_{i}
$$

where $\tilde{\varepsilon}_{i}=\tilde{u}_{i}-\beta \tilde{v}_{i}$ is the (transformed) combined error term.

This model fits again our measurement error framework as in (3), hence we can apply the CALS framework here as well. 
Note that although this estimator is consistent, there might be efficiency considerations to take into account. The fact that the measurement error variance is heteroskedastic translates into the combined error term $\tilde{\varepsilon}_{i}$ not having a unique variance across observations, due to the transformation of the equation error terms $\left(u_{i}\right)$. In future research, one could try to obtain robust standard errors for inference.

In order to obtain a feasible version of the CALS estimator one needs a consistent estimator of $\sigma_{v}^{2}$ or $\sigma_{v i}^{2}$. We used as the estimator for $\sigma_{v i}^{2}$ the sample variance of firm $i$, whereas the estimator for $\sigma_{v}^{2}$ was taken as the average over the $\hat{\sigma}_{v i}^{2}$ 's. ${ }^{15}$

\section{Results for the administrative cost-claims relationship}

We first present the results concerning the model relating administrative costs and claims payments, focusing on the cost efficiency of the insurance companies.

In Table 4 we present the results for the administrative cost-claims payments relationship. We performed OLS with average data $\left(b_{A V E}\right)$, CALS in the untransformed $\left(b_{C A L S}\right)$ and transformed model $\left(\tilde{b}_{C A L S}\right)$ and IV-GMM. As an illustration of the importance of the measurement error bias, we include the results of performing OLS with all observations $\left(b_{O L S}\right)$.

We observe that the slope coefficient in the OLS regression is very low, the IV coefficient is about 5 times higher. Further, the intercept here corresponds to almost $85 \%$ of the sample mean of the independent variable. In the case of administrative costs we observe that using average data might lead to biased results. Note that the results, using average data, are very similar to the ones obtained by von Ungern-Sternberg [1994] for a different time period. However, the results from the consistent estimators suggest that there might still be considerable downward bias (of around 20\%) of the slope coefficient using average data.

Table 4. Results of Estimation (administrative costs-claims relationship) ${ }^{\mathrm{a}}$.

\begin{tabular}{lll}
\hline Model & \multicolumn{1}{c}{$\hat{\alpha}$} & \multicolumn{1}{c}{$\hat{\beta}$} \\
\hline$b_{A V E}$ & $3.06^{*}$ & $0.12^{* * *}$ \\
& 1.73 & 0.05 \\
$b_{C A L S}$ & 2.38 & $0.14^{* * *}$ \\
& 2.00 & 0.06 \\
$\tilde{b}_{C A L S}$ & 2.10 & $0.15^{* * *}$ \\
& 1.63 & 0.06 \\
$b_{I V-G M M}$ & $2.36^{* * *}$ & $0.15^{* * *}$ \\
& 0.74 & 0.02 \\
$b_{O L S}$ & $6.18^{* * *}$ & $0.03^{* * *}$ \\
& 0.30 & 0.008 \\
\hline
\end{tabular}

${ }^{\mathrm{a}}$ The number of observations are 19 for $b_{A V E}$, $b_{C A L S}$ and $\tilde{b}_{C A L S}$. For $b_{I V-G M M}$ and $b_{O L S}$ they are 342. Estimated standard errors are reported below the coefficient value. ${ }^{*}$ represents statistically significant at $10 \%,{ }^{* *}$ at $5 \%$ and ${ }^{* * *}$ at $1 \%$. 
The estimators using CALS or IV present similar results with slope coefficients of 0.15 and the constant representing about $30 \%$ of the sample mean of administrative costs. Regarding statistical significance, we can say that the slope coefficient is highly significant for all estimation techniques, whereas the theoretically justified constant is empirically important (at least $28 \%$ of the sample mean) in all cases, but statistically significant only when using the instrumental variable technique.

\section{Results for the premium-claims relationship}

Regarding the relationship between premium rates and claims we have argued above that prevention expenses should not be considered like other cost components such as administrative expenses and commissions. This is why we focused on the relation between net premium and claims payments. It could be argued that one should include a time trend in the model, as there have been (gradually) important reductions over time in premium rates among the CPI. Including time in the regressions alters the relevant parameters $(\alpha$ and $\beta$ ) only marginally. We therefore opted to present results not including a time trend. ${ }^{16}$

In Table 5 we present the results for the different estimation techniques. Again we performed OLS with average data $\left(b_{A V E}\right)$, CALS in the untransformed $\left(b_{C A L S}\right)$ and transformed model $\left(\tilde{b}_{C A L S}\right)$, using time averages for each CPI. Further, we performed IV-GMM estimation on all observations. As an illustration we included OLS with all observations $\left(b_{O L S}\right)$. The Appendix presents the results using the premium data.

The table confirms the expected results. OLS on all observations yields a very low slope coefficient ${ }^{17}(\hat{\beta})$, whereas the intercept concentrates most of the explanation of the model. In fact, the intercept in the OLS model corresponds to almost $75 \%$ of the sample mean of the independent variable. When using average data, the situation already changes dramatically.

Table 5. Results of Estimation (net premium-claims relationship) ${ }^{\mathrm{a}}$.

\begin{tabular}{lll}
\hline Model & $\hat{\alpha}$ & \multicolumn{1}{c}{$\hat{\beta}$} \\
\hline$b_{A V E}$ & $14.80^{*}$ & $1.15^{* * *}$ \\
& 7.38 & 0.20 \\
$b_{C A L S}$ & 8.56 & $1.33^{* * *}$ \\
& 8.77 & 0.24 \\
$\tilde{b}_{C A L S}$ & $5.04^{* * *}$ & $1.38^{* * *}$ \\
& 5.12 & 0.19 \\
$b_{I V-G M M}$ & $9.06^{*}$ & $1.31^{* * *}$ \\
& 5.15 & 0.16 \\
$b_{O L S}$ & $40.32^{* * *}$ & $0.41^{* * *}$ \\
& 1.82 & 0.05 \\
\hline
\end{tabular}

${ }^{\mathrm{a}}$ The number of observations are 19 for $b_{A V E}, b_{C A L S}$ and $\tilde{b}_{C A L S}$. For $b_{I V-G M M}$ and $b_{O L S}$ they are 342 . Estimated standard errors are reported below the coefficient value. ${ }^{*}$ represents statistically significant at $10 \%,{ }^{* *}$ at $5 \%$ and ${ }^{* * *}$ at $1 \%$. 
The slope coefficient increases to a level above one and the intercept drops to less than $30 \%$ of the sample mean of net premiums. We observe that $b_{A V E}$, though a better estimate still seems to be biased. The three consistent estimators $\left(b_{C A L S}, \tilde{b}_{C A L S}\right.$ and $\left.b_{I V-G M M}\right)$ show slope coefficients of roughly 1.3. Note that the OLS-adjustment on the transformed model $\left(\tilde{b}_{C A L S}\right)$ leads to the highest slope coefficient and a constant that represents merely $10 \%$ of the sample average of the independent variable. Note that $\tilde{b}_{C A L S}$ and $b_{I V-G M M}$ have slope coefficients that are statistically different from one at the $10 \%$ level. Finally, the results confirm our concern on heteroskedastic measurement error, in that $\tilde{b}_{C A L S}$ seems to be more robust. It detects a significant and theoretically justified constant, even though its value is the lowest among all the estimators.

We tried including other control variables in this admittedly parsimonious framework. Inclusion of population and a dummy for urban areas as control variables did not affect the coefficient values significantly. ${ }^{18}$

We next turn to the comparison of our results on the CPIs with the private insurance providers.

\section{Comparison with private insurance providers}

In this section we shall use the results estimated above to extrapolate the level of administrative costs and (net) premiums for a hypothetical CPI with the level of damages of the private insurers. As mentioned in Section 2, data for the private insurance providers correspond to averages over all firms and cantons for the period 1984 to $1995 .{ }^{19}$

Before proceeding with this comparison we need to justify that the private and public insurance providers are indeed comparable, even though they operate in geographically different areas. As was mentioned before, there is no apparent selection bias within the privately served cantons, since the institutional framework was chosen mainly on historical grounds. For example, three of the five mountain cantons of Switzerland (cantons with their main territory lying in the Alps) have private insurance providers, but also one of the three predominantly urban cantons is served by private firms. ${ }^{20}$

Further, two financial arguments could imply that the two institutional frameworks are not comparable: first, since the CPIs are public monopolies they could operate under conditions where a private firms could not; specifically earning a low or zero rate of return. Second, the number of firms operating in the private cantons could be too small, such that collusive behavior among the firms could lead to higher premium rates.

Regarding the rate of return of the CPIs it is clear that most publicly owned companies do not distribute profits. Any excess earnings are ploughed directly into reserves. In this light, two observations support the claim that the CPIs operate under similar conditions as private firms. First, although public monopolies, CPIs have not, in the years of their existence, received any subsidy from the general public sector for their operation. Further, the public insurance companies have accumulated substantial reserves, which currently amount to over 6 billion SFr. ${ }^{21}$ It is these accumulated reserves (and the interest income they earn thereon) that allowed the CPIs to lower further their premium rates in recent years. We would therefore argue that the CPIs do indeed earn a rate of return comparable to private firms. 
Table 6. Comparison with private insurance providers cts/SFr. 1'000 SI.

\begin{tabular}{lccc}
\hline Comparison & Claims & Net premium & Adm. costs \\
\hline Avg. of private & 58.19 & 102.8 & 31.00 \\
Avg. of CPI & 32.90 & 49.59 & 6.10 \\
Forecast (IV) & & 85.56 & 10.80 \\
Forecast (AVE) & & 81.65 & 10.32 \\
Difference (IV) & & $20.15 \%$ & $187.05 \%$ \\
Difference (AVE) & & $25.91 \%$ & $200.44 \%$ \\
\hline
\end{tabular}

Concerning a potential oligopoly driving up premium rates in the private cantons, one can note that, as of 1994, over 30 companies where active in the segment within the private cantons. Appendix A3 includes a list of the eight most important insurers. Combined they represent almost $80 \%$ of insured capital in the private cantons. We would therefore argue that the structure of the market could be described as "real world competition".

Finally, it should be noted that the regulatory framework is almost identical for the two regimes. There is no specific regulation within the privately served cantons. Similarly, the only regulation that some of the CPIs face is a control on the total amount of reserves. However, the limits on reserves, where applicable, are generally very generous and do not, in our opinion, influence our analysis.

Having argued that the public and private regimes are indeed comparable we present in Table 6 the results of the comparison exercise. We present comparisons using the estimation results of the instrumental variables estimation and OLS with average data.

\section{Administrative costs}

The true administrative cost level of the CPI is equal to $6 \mathrm{cts} / \mathrm{SFr}$. 1'000 SI. With the damage levels of the private insurers this would increase to slightly more than $10 \mathrm{cts}$. Hence, only a small fraction of the total difference in administrative and sales costs can be explained by differences in claims levels. Of the initial difference of $25 \mathrm{cts}$, more than $20 \mathrm{cts}$ remain unexplained. In this market, state monopolies clearly lead to a substantial cost saving for the customer. To understand what this cost saving means in absolute numbers, note that the total stock of insured housing capital of the CPIs in 1998 was of the order of 1'500 billion SFr. The saving in administrative and sales cost of $20 \mathrm{cts}$ thus represents a cost saving of around 300 million Francs (US\$ 200 million) per year.

\section{Net premiums}

We obtain similar results when comparing net premiums according to Table 6. The hypothetical net premium rate of a CPI with the damage rate of the private insurers is equal to $86 \mathrm{cts}$. This implies that the private insurance providers are about $20 \%$ more expensive than a CPI would be with similar claims levels. Note that the average damage rate of the three CPIs with the highest claims level (Lucerne, Jura and Nidwalden) is equal to 53 cts. This is 
slightly more than the average of the private providers (50 cts). The average net premium rate of these three CPIs is equal to 80 cts as compared to 103 for the private providers. Our results are thus quite plausible.

The estimated difference in net premium levels $(103-86=17 \mathrm{cts})$ is thus only marginally smaller than the difference in costs savings ( $20 \mathrm{cts}$ ) computed in the previous section. The missing $3 \mathrm{cts}$ are due to the fact that cantons with higher claims levels require more reserves than cantons with lower claims levels.

Finally, we can observe that the predicted $\mathrm{C} / \mathrm{P}$ ratio for a $\mathrm{CPI}$ with the claims rate of the private insurers is about $68 \%,{ }^{22}$ whereas the effective $\mathrm{C} / \mathrm{P}$ ratio for the private insurers is only $57 \%$.

Note that it is not possible to perform comparisons for each canton where housing insurance is offered by private firms. The private insurers have set up a "pool" for elementary damage insurance. For this category of damage, they charge the same premium rate across all cantons even though the effective risk exposition varies substantially. This is an important source of cross-subsidies across cantons. An individual comparison of the cost efficiency by canton is thus not warranted. No such pool exists among the CPIs.

Thus the results on the premium-claims relationship confirm the results obtained for administrative expenses. The CPIs operate with greater cost efficiency and these lower costs do indeed translate into lower premium rates.

\section{Some remarks on damage prevention}

The previous analysis was based on the implicit assumption that the reductions in claims due to the higher prevention expenditures were no larger than the preventive expenditures themselves. It would of course be interesting to test whether this is the case.

Ideally one would wish to specify an econometric model to estimate the efficiency of expenditures on prevention. Unfortunately, we do not have the necessary data for such an exercise. An alternative approach would be to compare the level of claims in two areas that are similar in most respects. We did this for Geneva (private) and Lausanne (CPI).

According to data presented in Schips [1995], the average claims rate for the period 1984 to 1993 in Geneva was $37 \mathrm{cts}$. The claims rate for the urban area of Lausanne, which has approximately the same urban structure as Geneva is equal to $21 \mathrm{cts}$. The difference with Geneva is thus $37-21=16$ cts. Prevention expenses in the canton Geneva are of the order of $6 \mathrm{cts}$, in Lausanne they are $13 \mathrm{cts}$. The difference is thus $7 \mathrm{cts}$.

The difference in prevention expenditures ( $7 \mathrm{cts}$ ) is considerably lower than the difference in claims ( $16 \mathrm{cts})$. These numbers would suggest that the reduction in claims due to better prevention exceeds the increase in prevention expenditures by $16-7=9 \mathrm{cts}$.

In view of these observations it seems fair to assume, that the reduction in damages is probably much larger than the simple difference in preventive expenditures suggests. The comparisons above are thus most probably heavily biased against the CPIs.

\section{Conclusions}

We set out to compare the cost efficiency of public and private property insurance providers in Switzerland. The public providers (CPIs) work with premium rates that are approximately 
$60 \%$ of the ones from private insurers. However, private insurers show claims payments that are almost double the ones observed for the CPI. This implies that the commonly used claims-premium ratio is virtually identical between public and private providers. One could therefore argue that, given the similarity in the claims-premium ratio, there is no case for differences in cost efficiency.

We argue that the use of the claims-premium ratio can lead to strongly biased results. First, one can observe that the CPI spend considerably higher amounts on prevention than do their private counterparts. These expenses cannot be considered as simple cost components, such as administrative costs and commissions, since they lead to lower damage rates. Working with net (of prevention) premium income is thus more adequate. Further, in order to use the claims-premium ratio, one assumes that the elasticity between claims payments and premium income is equal to one. However, there are sound theoretical reasons to believe that this elasticity is in fact less than one. Administrative costs and commissions, as a component of the premium, can be divided conceptually into two parts; one which is independent of the claims level (e.g. the acquisition of new customers), and one which depends on the claims level (e.g. settling claims). Hence, when regressing premium income on claims payments, one would expect a positive intercept.

In order to test these issues, we use a simple model of a linear relationship between premium income (or administrative costs and commissions) and claims. We assume (and the data confirm) that premium rates are a function of the "normal" or "permanent" level of claims. This implies first that premium income (or administrative costs) varies much less over time than do claims, and second that annual observations on claims payments are a noisy signal of the true underlying "permanent" variable.

This setup fits a measurement error framework, and we can use techniques that deal with this issue. An additional feature we include in our model is the fact that the noisiness of the signal is different across firms, i.e. the measurement errors are heteroskedastic.

We estimate our model using a data set of the 19 CPIs in Switzerland over the period 1981 to 1998 . We focus on the relationship between net premium income and claims payments and administrative costs and claims payments, using instrumental variables (IV) and consistent adjusted least squares (CALS) estimation procedures.

We find that measurement error bias is an important issue in our data set, even when using average data for each firm. Further, the results indicate that the elasticity between claims payments and premium income is less than one. For net premium income we obtain a coefficient on claims payments of around 1.3, whereas the constant represents around $10 \%$ of the sample average. In the case of administrative costs, we obtain a coefficient on claims payments of 0.15 , and a constant representing about $30 \%$ of the sample average.

We next performed an extrapolation of our estimation results for an hypothetical CPI with a level of damages of the private insurers. We sustain the claim that the CPIs and private firms operate under similar conditions. This allows to compare the estimated administrative costs and net premium rates with the effectively observed ones for the private firms. We find that private property insurance providers in Switzerland are about $20 \%$ more expensive than a CPI with similar damage levels would be. In the case of administrative costs, the data show that the private providers spend around $20 \mathrm{cts}$ per SFr. 1'000 of sum insured more than do the CPIs. Only 4 cts of these 20 cts can be explained with differences in the claims level. 
Given the insured stock of housing capital in the cantons with CPIs this implies annual cost savings of around 300 million francs per year.

Finally, it should be noted that the above results implicitly assume that prevention expenditures do not lead to reductions in claims payments that are higher than the former. From a comparison between two similar areas, Geneva (private) and Lausanne (CPI), we see that there is a difference of 16 cts in the claims rates, whereas the difference in the prevention rates is only $7 \mathrm{cts}$. This suggests that the reductions in damage are probably larger than the differential in prevention expenditures. This suggests that our comparisons are strongly biased against the CPIs.

\section{Appendix}

A1. List of private and public cantons.

\begin{tabular}{|c|c|c|c|c|}
\hline Canton & CPI & Private & Urban & Mountain \\
\hline Zurich & $\mathrm{x}$ & & $\mathrm{x}$ & \\
\hline Bern & $\mathrm{x}$ & & & \\
\hline Lucerne & $\mathrm{x}$ & & & \\
\hline Nidwalden & $\mathrm{x}$ & & & \\
\hline Glarus & $\mathrm{x}$ & & & $\mathrm{x}$ \\
\hline Zug & $\mathrm{x}$ & & & \\
\hline Fribourg & $\mathrm{x}$ & & & \\
\hline Solothurn & $\mathrm{x}$ & & & \\
\hline Basel-City & $\mathrm{x}$ & & $\mathrm{x}$ & \\
\hline Basel-Land & $\mathrm{x}$ & & & \\
\hline Schaffhausen & $\mathrm{x}$ & & & \\
\hline Appenzell (AR) & $\mathrm{x}$ & & & \\
\hline St. Gallen & $\mathrm{x}$ & & & \\
\hline Graubünden & $\mathrm{x}$ & & & $\mathrm{x}$ \\
\hline Aargau & $\mathrm{x}$ & & & \\
\hline Thurgau & $\mathrm{x}$ & & & \\
\hline Vaud & $\mathrm{x}$ & & & \\
\hline Neuchatel & $\mathrm{x}$ & & & \\
\hline Jura & $\mathrm{x}$ & & & \\
\hline Geneva & & $\mathrm{x}$ & $\mathrm{x}$ & \\
\hline Appenzell (AI) & & $\mathrm{x}$ & & \\
\hline Schwyz & & $\mathrm{x}$ & & \\
\hline Obwalden & & $\mathrm{x}$ & & $\mathrm{x}$ \\
\hline Uri & & $\mathrm{x}$ & & $\mathrm{x}$ \\
\hline Ticino & & $\mathrm{x}$ & & \\
\hline Valais & & $\mathrm{x}$ & & $\mathrm{x}$ \\
\hline
\end{tabular}

Sources: von Ungern [1994] and SECO [2003].

Remaining cantons are foothills of the-alps or midland. 
A2. Results of gross premium-claims relationship.

\begin{tabular}{lcc}
\multicolumn{3}{c}{$\begin{array}{c}\text { Results of Estimation } \\
\text { (gross premium-claims relationship) }\end{array}$} \\
\hline Model & $\hat{\alpha}$ & $\hat{\beta}$ \\
\hline$b_{A V E}$ & $32.58^{* * *}$ & $1.09^{* * *}$ \\
& 2.21 & 0.06 \\
$b_{C A L S}$ & $22.26^{*}$ & $1.39^{* * *}$ \\
& 11.88 & 0.06 \\
$\tilde{b}_{C A L S}$ & $16.84^{* * *}$ & $1.51^{* * *}$ \\
& 4.78 & 0.18 \\
$b_{I V}$ & $26.92^{* * *}$ & $1.25^{* * *}$ \\
& 4.87 & 0.14 \\
$b_{I V-G M M}$ & $26.92^{* * *}$ & $1.25^{* * *}$ \\
& 4.97 & 0.15 \\
$b_{O L S}$ & $57.74^{* * *}$ & $0.36^{* * *}$ \\
& 1.69 & 0.04
\end{tabular}

${ }^{\text {a }}$ The number of observations are 19 for $b_{A V E}, b_{C A L S}$ and $\tilde{b}_{C A L S}$. For $b_{I V}, b_{I V-G M M}$ and $b_{O L S}$ they are 342. Estimated standard errors are reported below the coefficient value. ${ }^{*}$ represents statistically significant at $10 \%,{ }^{* *}$ at $5 \%$ and ${ }^{* * *}$ at $1 \%$.

A3. Major insurance companies operating in the private cantons.

\begin{tabular}{lc}
\hline Firm & $\begin{array}{c}\text { Insured Capital } \\
\text { million SFr. }\end{array}$ \\
\hline Basler & 45,692 \\
Elvia & 22,820 \\
Helvetia & 43,151 \\
Schw. Mobiliar & 48,096 \\
Schw. National & 13,951 \\
Union Suisse & 12,555 \\
Winterthur & 30,703 \\
Zurich & 13,366 \\
Total Majors & 230,335 \\
Total (non-CPIs) & 295,189 \\
\hline
\end{tabular}

Source: Federal Office of Private Insurance.

\section{Acknowledgments}

We wish to thank Ramses Abul Naga, José Anson, Marius Brülhart, Alex Georgiev, Alberto Holly, Christophe Kolodziejczyk and participants at the SMYE 2002, EARIE 2002 and IIOC 
2003 conferences for discussions. We acknowledge comments by an anonymous referee and brief, but very helpful, ones by Mark Watson and Bo Honoré. Remaining errors and omissions are our responsibility. Financial support was provided by the Swiss National Science Foundation Grant \#101412-100380.

\section{Notes}

1. Average C/P ratios for private insurers in Switzerland in the years 1989 to 1994, were 0.49 for legal protection and 0.74 for comprehensive insurance for airplanes, a difference of 25 percentage points.

2. The description below draws on von Ungern [2004]. More institutional details can be found there.

3. Note that the CPI's represent (as of 1990) more than $80 \%$ of housing insurance in Switzerland, measured in terms of insured housing stock. A list of the CPI and private cantons can be found in Appendix A1.

4. Figures here and below correspond to average claims and premium rates over the period 1984 to 1995.

5. Using standard $5 \%$ levels of statistical significance.

6. We tested whether we can model the evolution of claims payments as in (2), regressing, for each firm, the annual claims on a constant and a time trend. We observed that for all but two firms the constant is significant but the time trend is not. Breusch-Godfrey tests on serial correlation (of order 2) did not indicate signs of serial correlation. However, there are strong indications that the variances of claims payments across firms are different. A test of equality of variances showed that 9 firms had significantly different variances from the mean of the sample.

7. This is often called attenuation.

8. Described by $\sigma_{x^{*}}^{2}$ for the permanent level of claims and $\sigma_{v}^{2}$ for the measurement error. Note that the term "second moment" is not completely correct here if $x^{*}$ is a fixed number, in that case $\sigma_{x^{*}}^{2}$ is a constant.

9. However, Malinvaud [1980] wrote: "Thus, ..., we must find instrumental variables which are uncorrelated with the errors affecting the variables, but are strictly correlated with the true values of these variables. In practice, these considerations are often contradictory, and this greatly restricts the usefulness of the method". (Emphasis from the authors).

10. Note that the existence of serial correlation in the form of $M A(p)$ would allow to use observations at time $\tau>t+p$ or $\tau<t-p$ as valid instruments. However, claims do not show signs of serial correlation, see FN 7 .

11. We thank Mark Watson for suggesting this instrument. Note that we concentrate the available information into one variable, thus reducing the number of instruments to a minimum. However, formulating the instrument in this way does not allow for eventual panel data estimators, since $\operatorname{cor}\left(x_{i t}, w_{i t}\right)=-1$ by construction.

12. The F-statistic for $w_{i t}$ in a regression of $x_{i t}$ on $w_{i t}$ in our sample is 854 , which is considerably above a value of 10 , proposed as a critical value for possibly weak instruments.

13. The asymptotic distribution of the estimator of the slope coefficient can be found in Meijer and Wansbeek [2000].

14. A similar model could be formulated using all the observations in our data set and not just the firm specific averages. However, the relevant information on $x_{i}^{*}$ is contained in the firm specific averages. Using the yearly data, just introduces more noise. Results using all observations revealed to be very sensitive to changes and therefore not reliable.

15. Note that this estimator for $\sigma_{v i}^{2}$ assumes $x_{i}^{*}$ to be non-stochastic. Abul Naga [2000] presents alternative estimators for stochastic $x_{i}^{*}$ 's based on the variance of first differences. Using these alternative estimators for the measurement error variance only marginally altered our results.

16. Results of the regressions including a time trend can be obtained from the authors upon request.

17. The slope coefficient in the OLS model is about one third of the one obtained using IV.

18. Results can be obtained from the authors upon request.

19. For reasons of comparability, we took the same period for the average values of the CPIs.

20. See Appendix A1 for details.

21. This represents over five times the damage claims in the exceptionally bad year 1999. See von Ungern [2004] for more details. 
22. Note that the C/P ratio of the three CPI's with the highest claims level (Lucerne, Nidwalden and Jura) is still $65 \%$.

\section{References}

ABUL NAGA, R.H. [2000]: "Galtonian Regression of Intergenerational Income Linkages: Biased Procedures, a New Estimator and Mean-Square Error Comparisons," Cahiers de Recherches Economiques 00.13, Université de Lausanne.

ASSOCIATION OF BRITISH INSURERS [1996]: Insurance Statistics Year Book 1985-1995.

COASE, R.H. [1960]: “The Problem of Social Cost,” Journal of Law and Economics, October, 1-44.

EPPLE, K and SCHAEFER, R. [1996]: "The Transition from Monopoly to Competition: The Case of Housing Insurance in Baden-Wü Rttemberg,” European Economic Review, 40(April), 1123-1131.

FELDER, S. [1996]: "Fire Insurance in Germany: A Comparison of Price-Performance Between State Monopolies and Competitive Regions," European Economic Review, 40(April), 1133-1141.

FEDERATION FRANCAISE DES SOCIETES D'ASSURANCES [1998]: Le marché de l'assurance des habitations en 1998 - Résultats détaillés. APSAD.

GRILICHES, Z. and HAUSMAN, J. [1986]: "Errors in Variables in Panel Data," Journal of Econometrics, 31(February), 93-118.

KAPTEYN, A. and WANSBEEK, T.J. [1984]: "Errors in Variables: Consistent Adjusted Least Squares (CALS) estimation," Communication in Statistics Theory and Methods, 13, 1811-1837.

KIRCHGAESNER, G. [1996]: "Ideologie und Information in der Politikberatung: Einige Bemerkungen und ein Fallbeispiel,” Diskussionspapier Nr. 9605, Universität St. Gallen.

MALINVAUD, E. [1980]: Statistical Methods of Econometrics. Amsterdam: North-Holland.

MEIJER, E. and WANSBEEK, T. [2000]: “Measurement Error in a Single Regressor,” Economics Letters, 69(June), 277-284.

SCHIPS, B. [1995]: "Ökonomische Argumente für den wirksamen Wettbewerb auch im Versicherungszweig "Gebäudefeuer und Geb äudeelementarschäden,” Universität St. Gallen.

SECO [2003]: "Neue Regionalpolitik—Schlussbericht”, elaborated by Brügger and Partner.

STAIGER, D. and STOCK, J. [1997]: “Instrumental Variables Regression with Weak Instruments," Econometrica, 65(May), 557-586.

UNESPA [1994]: Estadistica de Seguros Privados.

VON UNGERN-STERNBERG, T. [1994]: "Die Kantonalen Geb äudeversicherungen. Eine ökonomische Analyse," Cahiers de recherches économiques No 9405, Université de Lausanne.

VON UNGERN-STERNBERG, T. [1995]: "Kritische Überlegungen zu dem Gutachten von Professor Schips über die kantonalen Geb äudeversicherungsmonopole," Cahiers de recherches économiques No 9502, Université de Lausanne.

VON UNGERN-STERNBERG, T. [2004]: Efficient Monopolies-The Limits of Competition in the European Property Insurance Market. Oxford University Press.

WANSBEEK, T. and MEIJER, T. [2000]: Measurement Error and Latent Variables in Econometrics. Advanced Textbooks in Economics Vol. 37. Amsterdam: Elsevier Science. 